\title{
Quantification of function in normal and infarcted regions of the left ventricle
}

\author{
JUHANI HEIKKILÄ ${ }^{1}$, BURTON S. TABAKIN ${ }^{2}$, and PAUL G. HUGENHOLTZ \\ From the Thoraxcenter, University Hospital Dijkzigt, University of Rotterdam, \\ Rotterdam, The Netherlands
}

\begin{abstract}
AUTHORS' SYNOPSIS The extent to which non-functioning or infarcted myocardial segments impose a detrimental load on left ventricular performance is not easily measured and its significance may be underestimated. A method for quantifying contractility in multiple segments of the left ventricle and for assessing the role of the resulting ventricular asynergy was investigated in 15 openchested pigs with experimental myocardial infarction. High-speed cineradiography of metal clips and cineventriculography showed normal systolic epicardial shortening and transmural wall thickening to an average $15.8 \%$ and $31.7 \%$ respectively from their end-diastolic values. An unexpected degree of thickening of the left ventricular wall $(31.2 \%$ of total systolic thickening) was observed in the isovolumic phase. Isoproterenol enhanced contraction mechanics markedly, again mostly during the isovolumic phase. The changes in epicardial segment length and wall thickness completely separated transmural infarction areas from adjacent or remote regions with normal muscle function $(\mathrm{P}<0.001)$. Ventricular asynergy occurred, and often reached its maximum extent, in the isovolumic phase. Force-velocity analysis of muscle function also confirmed significant deterioration of total ventricular function. Increased end-diastolic segment length in association with normal rate of contraction in the uninvolved muscle areas indicated compensating mechanism of the FrankStarling type to occur immediately after acute infarction. The clinical implications of the measurement of wall thickness changes during systole for the assessment of left ventricular function are discussed.
\end{abstract}

Traditional haemodynamic measurements of the left ventricular function, such as stroke volume, ejection fraction and Frank-Starling curves, deal with the performance of the entire heart as a pump. When more sophisticated indicators of cardiac muscle function such as the "forcevelocity' concept are applied to the intact left ventricle a synergic order of contraction of the heart muscle and a truly isovolumic phase of systole are assumed to take place (Sonnenblick, Parmley, Urschel, and Brutsaert, 1970; Mason,

\footnotetext{
+ Address for reprints: Dr. J. Heikkilä, Cardiovascular Laboratory, First Department of Medicine, University Central Hospital, Haartmanink 4, Helsinki 29, Finland.

2 Present address: Cardiopulmonary Unit, College of Medicine
} University of Vermont, Burlington, Vermont, U.S.A.
Spann, Zelis, and Amsterdam, 1970). However, in coronary artery heart disease, particularly after myocardial infarction, focal mechanical dysfunction has now been recognized as an inherent and fundamental factor (Tennant and Wiggers, 1935; Pairolero, McCallister, Hallermann, and Ellis, 1970). Such dysfunction is important in the development of cardiac failure and may cause the latter to occur even in a normal sized heart (Heikkilä, Luomanmäki, and Pyörälä, 1971). Thus the question arises how regional function of the left ventricular muscle mass may be assessed and measured.

When focal areas of the cardiac muscle are infarcted the disrupted and uncoordinated left 
ventricular contraction impairs the "efficiency" of the pump. Work is spent in changing shape rather than in the ejection of blood and thus may be termed 'wasteful' in lieu of 'useful' work. This difference becomes clinically obvious when a portion of the left ventricular wall remains noncontractile or when it balloons out during systole. In such circumstances neither the 'total' ventricular performance studies nor the 'forcevelocity' analysis are able to define whether the observed deterioration in function is due to a diffuse scarring of the muscle throughout the left ventricle - as found in widespread coronary artery disease - or to a combination of marked asynergy in circumscribed areas with a normal, or even compensatory supernormal, function of uninvolved regions. As modern surgical techniques have now made the resection of such nonfunctioning areas possible (Milstein, 1970), quantitative methods to determine the relative contribution of a damaged and an uninvolved segment to the generation of the total left ventricular function need to be developed.

A decrease in myocardial contractile function is associated with a reduction in the extent and the velocity of myocardial fibre shortening (Braunwald, Ross, and Sonnenblick, 1968;
Gault, Ross, and Braunwald, 1968). Therefore in this study, fibre shortening was first measured by means of radio-opaque markers placed on various epicardial segments of the left ventricle. Secondly, measurements were carried out on the extent and velocity of changes in transmural wall thickness, from clips placed on either side of the ventricular wall. In order to decide whether the change in left ventricular wall thickening was as informative as the extent of epicardial ventricular shortening, both were compared before and after myocardial infarction of the anterior wall and related to control measurements of the posterior wall. As left ventricular wall thickness may also be studied from single plane angiocardiograms obtained in clinical circumstances, the conclusions to be derived from this study should be applicable to regional myocardial function analysis in patients with clinical coronary artery disease.

\section{Methods}

Fifteen young fernale pigs (weighing $18-25 \mathrm{~kg}$ ) were anaesthetized in the fasting state with intravenous pentobarbital with one to two doses of $30 \mathrm{mg} / \mathrm{kg}$. Respiration was maintained via an

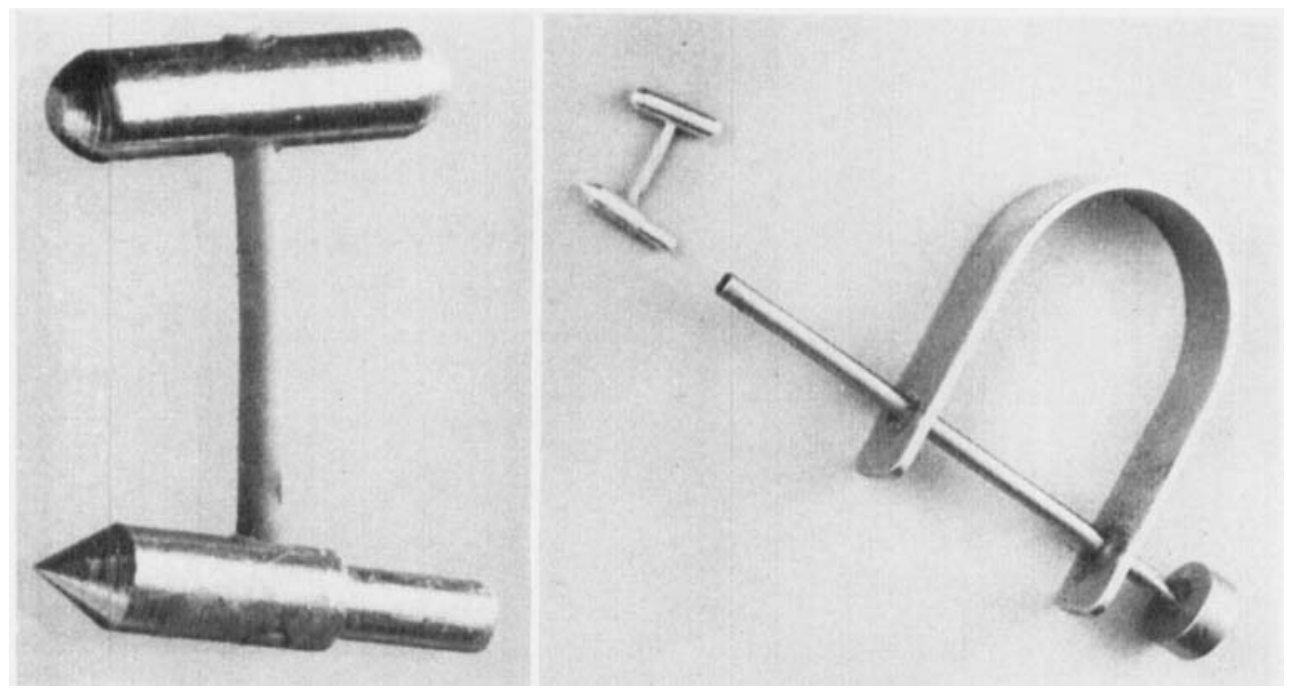

FIG. I A pair of aluminium clips connected with a rubber thread. The tail of the sharp-tipped inner clip fits tightly into the supporting shaft of the inserting instrument. Plunger within the shaft is used to detach the clip after piercing it through the ventricular wall. 
endotracheal tube connected to a Harvard respirator pump. A Dallons-Telco no. $8 \mathrm{~F}$ cathetertip micromanometer (frequency response $0-1,000 \mathrm{~Hz}$ ) was introduced through the right carotid artery into the left ventricle (LV) in all animals. From this catheter signal were recorded the LV pressure, the LV dp/dt (from an RC circuit with a time constant of $20 \mathrm{msec}$ ) and the intraventricular phonocardiogram. A no. 7 Cournand catheter was placed via the jugular vein into pulmonary artery or right atrium. A Lehman left ventriculography no. 7 catheter was placed into $L V$ via the right femoral artery.

After proper positioning of the catheters the chest was opened. Partial resection of the cartilaginous end of the sixth rib and spreading of the fifth intercostal space allowed a good exposure of the heart for the placement of the radio-opaque markers. The pericardium was opened near the mediastinum and the lateral edge secured to the lateral chest wall in order to move the lung away from the field.

Thereafter pairs of special metal clips connected by a $5-7 \mathrm{~mm}$ long rubber thread were placed into various areas of the heart. With the help of a harpoon-like instrument (the original idea for this device was given by Dr R. F. Rushmer, Seattle, Washington), the sharp tipped inner clip (Fig. 1) was rapidly introduced perpendicularly through the LV wall in such a manner that after insertion the inner clip rested against the endocardial surface and the outer clip of the pair against the epicardial surface. Three or four anterior clips were inserted in a row extending from the basilar to apical area to define accurately the mid-part and the borders of the induced myocardial infarction (Figs. 2 and 3 ). The compliant rubber band allowed easy separation of the clips during systole. In several animals kept for three months or more these clips were found in the same position as they had been placed. None of them became embedded in the tissues. Transmural LV wall thickness could be measured by the distance between the inner and outer parts of the clip pair. Distances between successive pairs of clips gave various epicardial and endocardial segment distances. In order to have the posterior and anterior clips on a same plane the posterior clips were inserted to the mid-ventricular posterior

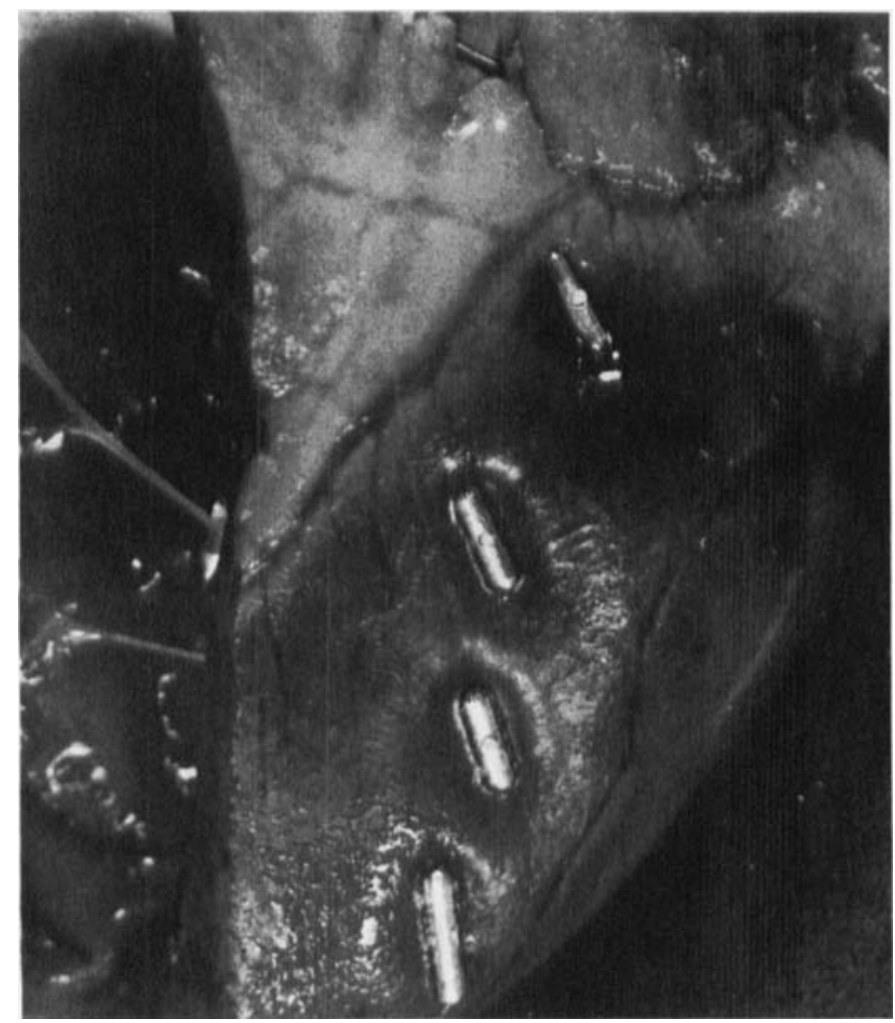

FIG. 2 A row of four epicardial marker clips in situ on the anterior surface of the left ventricle. Some epicardial oedema regularly developed after infarction, which is seen in this picture to surround the three lower clips. 
area when single plane cineradiography was used. Insertion was done from the lateral wall at right angles with the anterior clips in the instances where biplane $x$-ray technique was used. These modifications permitted the study with the least angulation from the desired observation planes.

The clip movements were recorded on high-speed cinefilms at 80 frames per second after careful positioning of the pig on the angiography table. The table could be rotated and tilted to adjust the $x$-ray beam to a direction perpendicular to the plane selected for study. The time of exposure of cineradiograms was recorded on a Siemens Oscillomink E 12-channel ink jet direct-writing recorder (frequency response $0-1,200 \mathrm{~Hz}$ ) at a paper speed of $500 \mathrm{~mm} / \mathrm{sec}$, together with the LV pressure, the intraventricular phonocardiogram, and the electrocardiogram leads aVL and aVR. This permitted correlation of $\mathrm{LV}$ wall motions with intraventricular pressure and sound events. Respiration was monitored and beats at the same end-expiratory phase were selected.

After a series of control cineradiograms a left cineventriculogram was performed with four successive injections of $5 \mathrm{ml}$. each of $76 \%$ Isopaque contrast material by means of a Contrac injector synchronized to inject these doses in diastole.

Circumscribed anterior wall damage was created between three pairs of anterior clips so that the upper and lower borders as well as the midportion of the infarcted area could be defined precisely by the clips. A metal bar of $8 \mathrm{~mm}$ diameter was cooled in liquid nitrogen and the surface of the heart was touched repeatedly for a few seconds at a time for a total of $10-15 \mathrm{~min}$. The damage was confirmed by direct observation of loss of muscle contraction, by changes in the surface electrocardiogram typical of acute ischaemia as well as by later pathological-anatomical examination. In four animals the freezing damage caused a transmural infarct, while in five animals the damage was restricted to the subepicardial layer of the $\mathrm{LV}$ wall. One more animal, in which freezing damage was not created successfully, was included in the control series only. One hour after freezing the cineradiographic, haemodynamic, and cineventriculographic records were repeated. In five other animals acute myo-

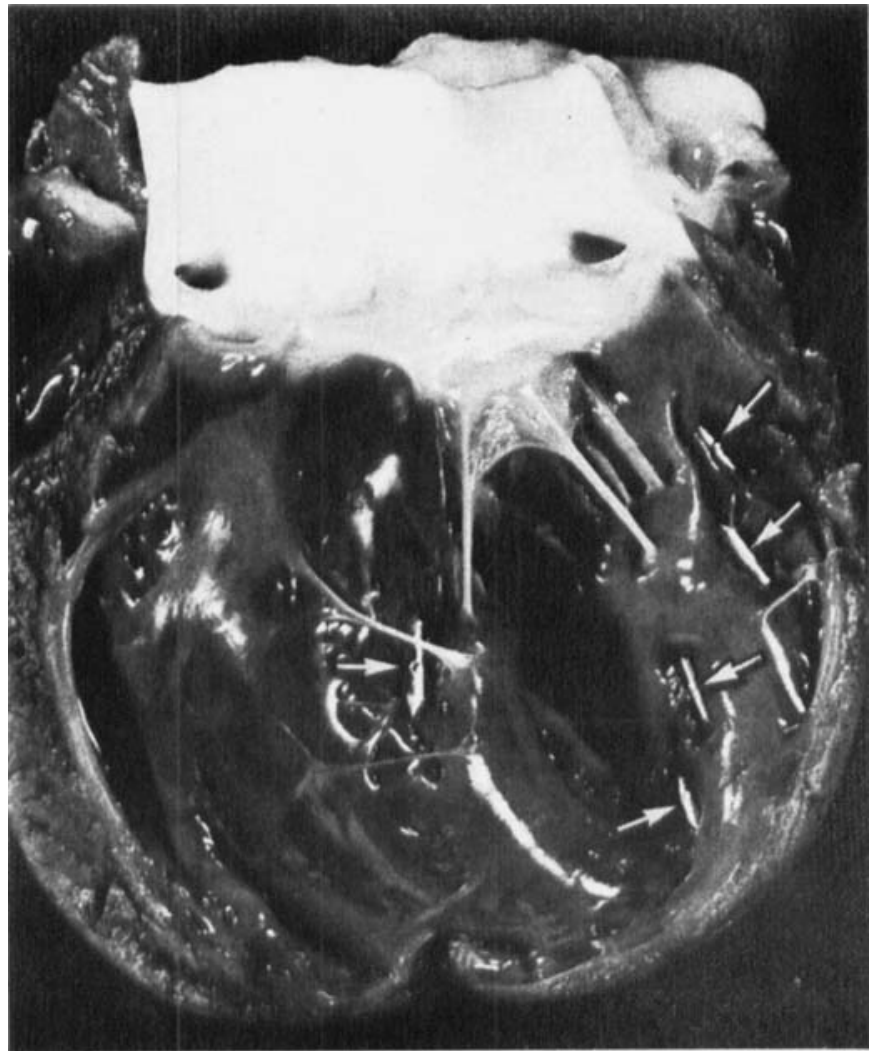

FIG. 3 A view into the carity of left ventricle displays the positioning of the clips against endocardial surface in the same heart as in Fig. 2. 
cardial infarction was caused by ligation of the anterior descending branch of the left coronary artery. These animals were studied $15 \mathrm{~min}$ after this intervention. Necropsy was carried out on all pigs and their hearts examined in order to verify proper placement of the clips and to perform a detailed microscopical examination.

For detailed cineradiographic analysis, beats at the end-expiratory phase, not preceded by extrasystoles or changes in the $R-R$ interval, were selected. The cinefilm frames were projected on an $x-y$ digitizing table and clip distances between the central points of each clip measured to the nearest $0.5 \mathrm{~mm}$. The film frames were separated by 12.5 msec intervals and were measured throughout that complete cycle period. In 100 double determinations the mean of the difference between the two measurements was 0.21 (SD 0.25) $\mathrm{mm}$. The accuracy of the measurement was thus of the order of $1 \%$. Due to clip placement through the base of the papillary muscle in three of the 14 animals the transmural thickness values could not be reliably measured in these instances.

End-diastole was defined to occur on the first frame exposed after the onset of the $Q$ wave. All results were expressed as percentage changes from their respective end-diastolic length so that they would be unaffected by any $x$-ray or optical magnification. Contraction velocities were determined by drawing a slope through the plotted sequential segment distances and the results expressed in muscle length per second. The isovolumic phase of the LV systole was defined as the period from the onset of intraventricular pressure rise, after the a-wave, to the onset of the LV ejection, as determined from the micromanometer recording. The onset of LV ejection was determined from the superimposed $\mathrm{dp} / \mathrm{dt}$ and $\mathrm{LV}$ pressure records by taking that point where their slope abruptly diminished. During the isovolumic phase at least four observation points were determined before a slope line was drawn. In the ejection phase the maximal steepness of the slope was taken. In Figs. 4 to 6 , pre-ejection period is used instead of the isovolumic phase because the timing of the film exposure at the onset of the true isovolumic phase varied somewhat in relation to the $Q$-wave, the interval between the successive cineframes being $12.5 \mathrm{msec}$. The end of $\mathrm{LV}$ ejection was recognized from the first vibrations of the intraventricular second heart sound. As a reflection of myocardial contractility peak $\mathrm{dp} / \mathrm{dt} / \mathrm{Kp}(\mathrm{K}=1)$ was calculated (Mason et al., 1970; Sonnenblick et al., 1970).

Microscopical examinations verified that the acute tissue damage induced by freezing was quite similar to myocardial infarction after coronary occlusion. The myocardial tissue showed oedema and necrosis with infiltration of leucocytes and erythrocytes.

\section{Results \\ Normal myocardium}

The mean values of the extent and the rate of epicardial segment shortening and of the transmural myocardial thickening from several left ventricular regions during the isovolumic phase of contraction and during the ejection phase of systole are given in Table 1 . The variations between normal anterior and normal posterior segments were minor, as shown in Table 3.

The sequential changes of epicardial segment shortening and of wall thickening during systole

T A B LE I

Extent and rate of segment shortening and of wall thickening in normal animals during cardiac systole (average of anterior and posterior walls)

\begin{tabular}{|c|c|c|c|c|c|c|c|}
\hline & \multicolumn{3}{|c|}{ Isovolumic phase } & \multicolumn{3}{|c|}{ Ejection phase } & \multirow{2}{*}{$\begin{array}{c}P \text { between iso- } \\
\text { volumic and } \\
\text { ejection phases }\end{array}$} \\
\hline & $N$ & $M e a n \pm S D$ & $P$ & $N$ & $M e a n \pm S D$ & $P$ & \\
\hline $\begin{array}{l}\text { Extent of segment shortening } \\
\text { (\% from end-diastolic length) }\end{array}$ & 24 & $2 \cdot 2 \pm 3 \cdot 7$ & \multirow[t]{2}{*}{$<0.001$} & 24 & $15 \cdot 8 \pm 4 \cdot 6$ & \multirow[t]{2}{*}{$<0.001$} & $<0.001$ \\
\hline $\begin{array}{l}\text { Extent of wall thickening } \\
\text { (\% from end-diastolic value) }\end{array}$ & 26 & $9 \cdot 9 \pm 7 \cdot 4$ & & 26 & $31 \cdot 7 \pm 10 \cdot 1$ & & $<0.001$ \\
\hline $\begin{array}{l}\text { Rate of segment shortening } \\
\text { (lengths/sec) }\end{array}$ & 23 & $0.47 \pm 0.85$ & \multirow[t]{2}{*}{$<0.001$} & 24 & $1.09 \pm 0.58$ & \multirow{2}{*}{$<0.005$} & $<0.01$ \\
\hline $\begin{array}{l}\text { Rate of wall thickening } \\
\text { (Jengths/sec) }\end{array}$ & 26 & $1 \cdot 96 \pm 1 \cdot 71$ & & 26 & $1.65 \pm 0.55$ & & NS \\
\hline
\end{tabular}

$\mathrm{SD}=$ standard deviation 


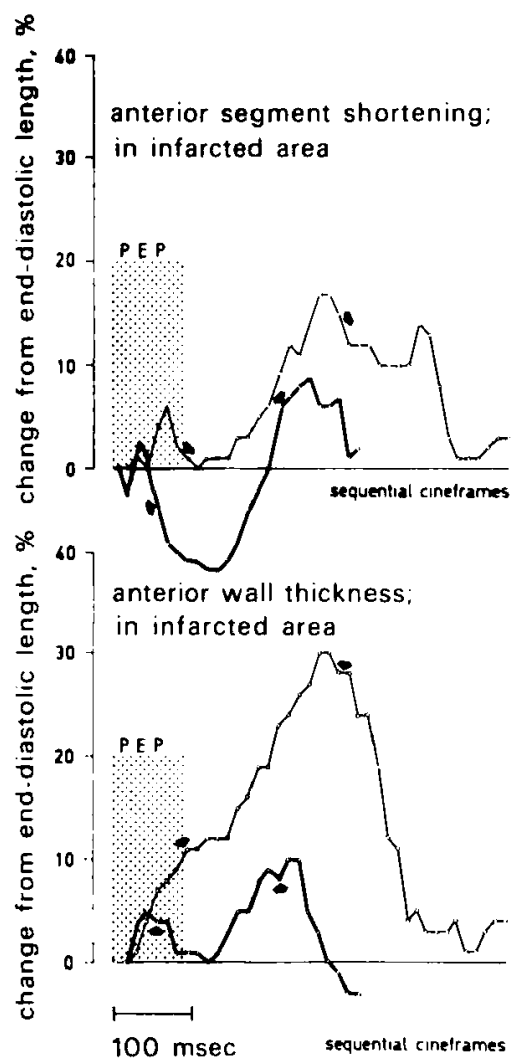

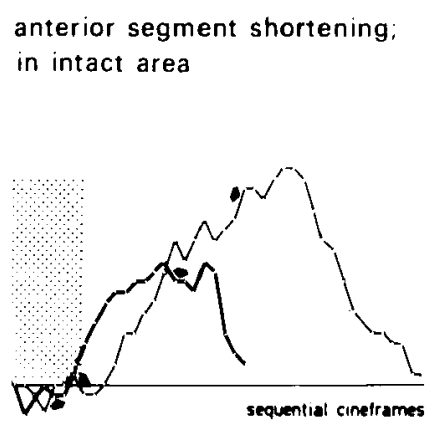

posterior segment shortening:
control area

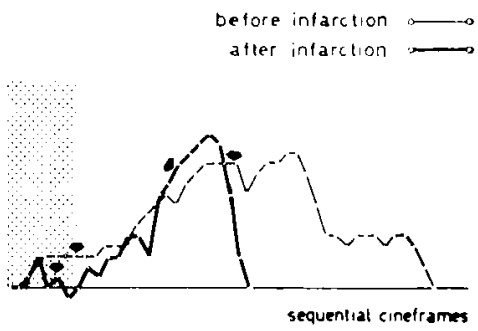

anterior wall thickness:

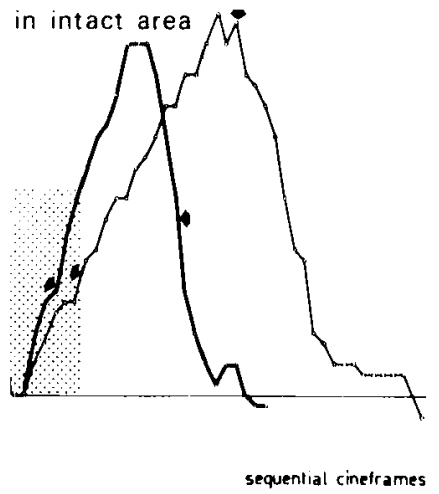

posterior wall thickness; control area

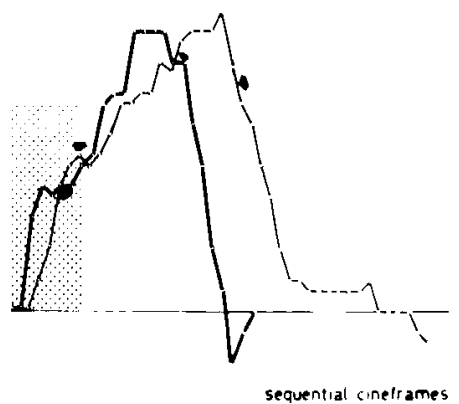

FIG. 4 A plot of fractional changes in the epicardial segment lengths and wall thicknesses measured by sequential cineframes throughout a complete cardiac cycle. The infarcted area shows systolic bulging instead of normal epicardial shortening or transmural thickening which are present both on the adjacent intact anterior segment and posterior wall. The shaded bar shows the duration of pre-ejection period (PEP) in control state from the onset of the $Q$ wave to aortic valve opening. The first arrows coincide with aortic valve opening and the second arrows with aortic valve closure.

and diastole of various segments are demonstrated in detail in three representative examples in Figs. 4, 5, and 6. Mechanical systole began a mean of $18.1 \mathrm{msec}$ after the onset of electrical ventricular activation with the onset of wall thickening. A similar electromechanical interval of $18.4 \mathrm{msec}$ was observed on the epicardial surfaces. The successive movements of different clips showed the normal ventricular contractions to be symmetric and synergic.

The degree of contraction of epicardial segments during the isovolumic phase was small $(13.9 \%$ of the total systolic contraction) and varied considerably. In contrast with this, the LV wall thickened considerably $(31.2 \%$ of total wall thickening) in the isovolumic phase. This occurred in every animal. The extent and velocity of wall thickening throughout systole markedly exceeded that of the epicardial surface at the same site (Tables 1 and 3). The maximum wall thickness always occurred before the aortic valve closure sound, preceding it by a mean interval of $38.4 \mathrm{msec}$. In contrast, epicardial shortening took place up to the moment of aortic valve closure and frequently continued after this time. This was found especially on the posterior epicardial surfaces where the mean delay after the occurrence of the aortic closure sound was $13.9 \mathrm{msec}$ before relaxation started. 
Changes in segmental contractile function by isoproterenol and acute anterior infarstion
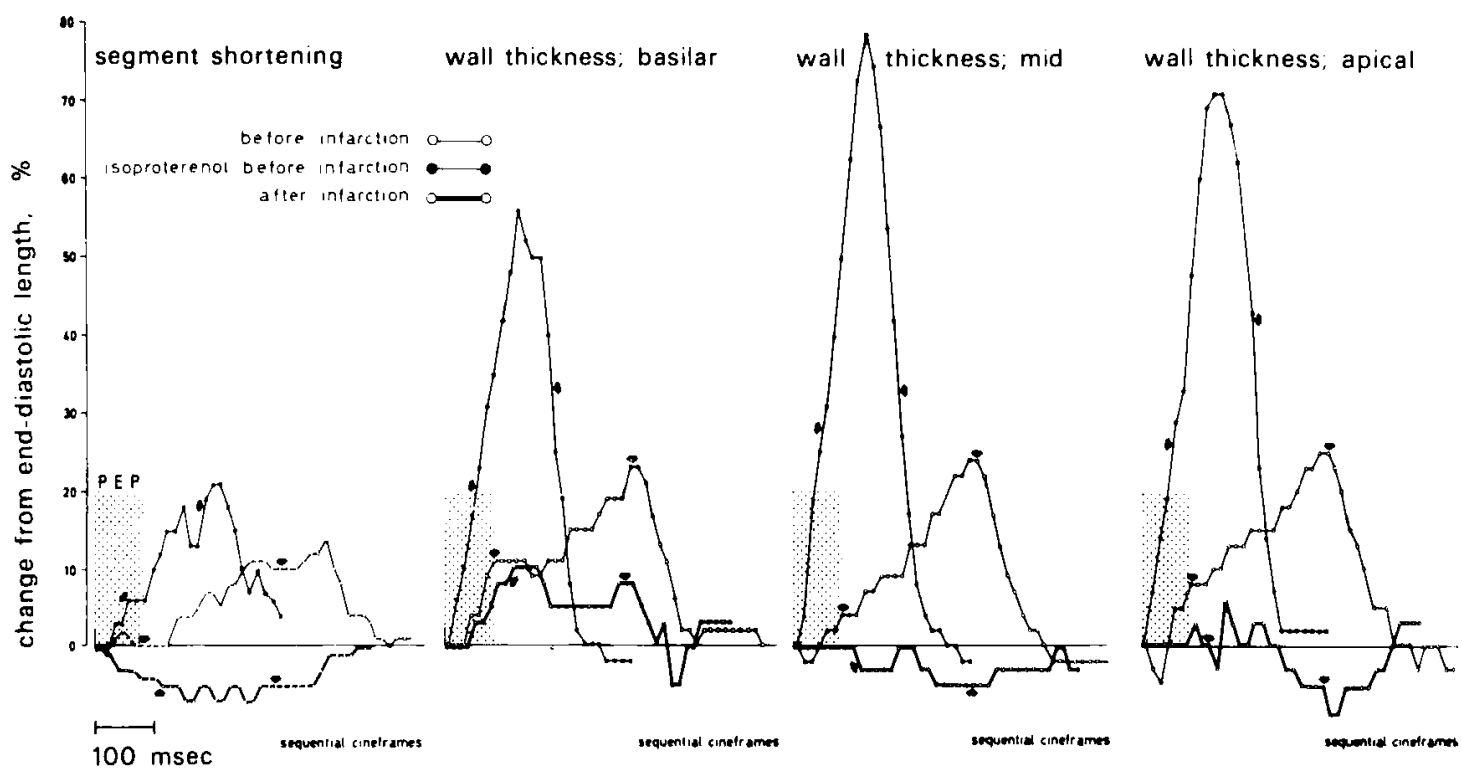

FIG. 5 Augmented anterior myocardial wall thickness extent and velocity recognize the effect of isoproterenol infusion on left ventricular contractility. Loss of contractile function follows occlusion of left anterior descending coronary artery. Note that marked alterations of ventricular segment dynamics take place early during the isovolumic phase of systole. The basilar thickness graph from the area at the border of infarct and normal muscle shows reduced contraction, while a complete loss of contractility and systolic thinning occurs in the centre of infarct at the mid-ventricular segment. For symbols see Fig. 4.

\section{Normal myocardium after isoproterenol infusion}

In five animals 1-2 ug/min isoproterenol was infused in order to evaluate the quantitative response of the normal and infarcted ventricle. Augmentation of the contractile force took place particularly in the isovolumic phase of systole (Table 2; Figs. 4, 5, and 9). The fraction of isovolumic thickening to total systolic thickening increased from $30 \%$ to $42 \%$ and the ratio of isovolumic shortening to total shortening from $17.5 \%$ to $44.7 \%$. The significant increase in the velocity of thickening during the isovolumic phase $(+194 \%)$ was comparable with that of the maximum LV wall thickening during the ejection phase $(+229 \%)$. The peaks of epicardial shortening and of wall thickening occurred earlier than in the control studies $(20.5$ and $13.0 \mathrm{msec}$ earlier respectively). Isoproterenol had a little effect on the extent or rate of epicardial segment shortening during the ejection phase. Peak $\mathrm{dp} / \mathrm{dt} / \mathrm{Kp}$ after isoproterenol increased by $+17 \pm 11 \cdot 1$ $\sec ^{-1}(+37.8 \% ; \mathrm{P}<0.02)$. When isoproterenol was infused after myocardial infarction no latent 'reserve' of contractile function in the completely infarcted area was uncovered. In fact, motion of the infarcted wall area remained unaltered in spite of the increased vigour of the uninvolved ventricular wall contraction.

\section{Myocardial infarction: abnormal segment func- tion}

As in the normal heart, the different parameters of epicardial segment shortening and of wall thickening behaved similarly even when abnormal ventricular function was induced (Table 3). All these variables differed significantly between the normal and infarcted regions (Table 3 ; Figs. 4, 5, 6, 7, 8, and 9). The changes were most evident during the ejection phase $(\mathrm{P}<$ 0.001 ). When only subepicardial damage had 


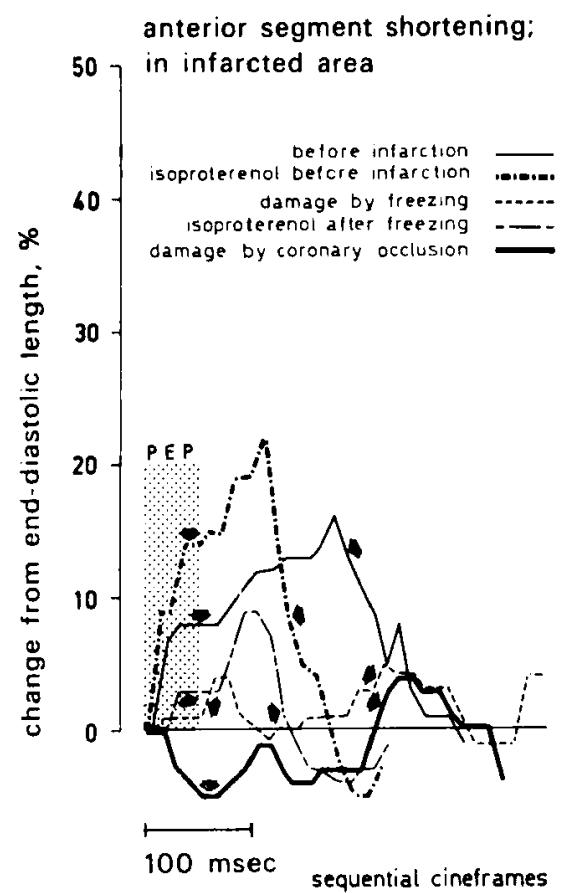

anterior wall thickness:

in infarcted area

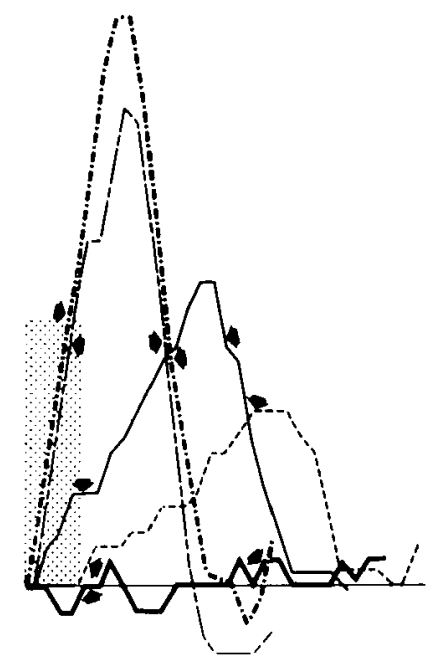

sequential cineframes posterior wall thickness:

control area

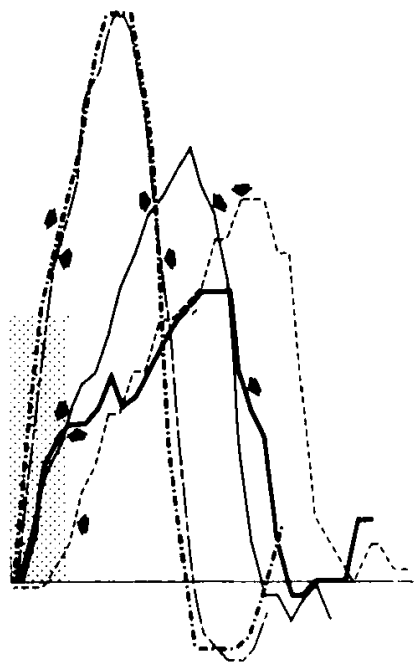

sequential cineframes

FIG. 6 Epicardial segment length and transmural wall thickness observations after partial anterior myocardial damage first induced by freezing, and after complete transmural infarction after ligation of the left anterior descending coronary artery in the same animal. Marked enhancement of contractility in the normal myocardium is induced by isoproterenol. Note the reproducibility of the isoproterenol effect on the mechanics of the normal (posterior) myocardium by the present technique. For symbols see Fig. 4 .

been induced the differences in wall thickening were not statistically significant (Table 3).

Myocardial infarction: altered ventricular dynamics

Loss of ventricular contractile function from acute myocardial infarction always caused segmental loss of the normal epicardial shortening and of wall thickening. This acute damage was rather more often a local akinesia than an extensive paradoxical systolic pulsation (Figs. $4,5,6,9$, and 10 ).

Some systolic thinning of the damaged region was observed in over half $(56 \%)$ of the transmural infarcts (Figs. 5, 6, 9, and 10); in the remainder $(44 \%)$ a 'motionless' akinesia seemed to prevail. It was remarkable to note that, when paradoxical systolic thinning of the infarcted wall occurred, it always started early (mean $26.6 \mathrm{msec}$ after the Q-wave) and also reached its greatest extent during the isovolumic phase (mean $56.8 \mathrm{msec}$ after the Q-wave). While stretching of the epicardial surface began at $23.3 \mathrm{msec}$ it reached its maximum later, at $98.9 \mathrm{msec}$ (Figs. 5 and 6), again in most cases before the aortic valve had opened.

The parameters of segment length and wall thickness in the posterior wall, which served as controls when anterior wall damage had been induced, did not differ significantly from those before infarction (Table 3; Figs. 4, 5, 6, and 10).

Overall impairment of left ventricular function was also reflected in alterations of the ventricular pressure pulse, end-diastolic segment dimensions and the force-velocity measurements. Peak dp/dt/Kp decreased consistently after the coronary ligation by a mean of $-14 \cdot 6 \pm 9 \cdot 2$ $\sec ^{-1}(-29.8 \% ; P<0.02)$, while the change was less and more variable when less myocardial damage was induced by freezing, mean $-3 \cdot 4 \pm$ 
524 Heikkilä, Tabakin, and Hugenholtz

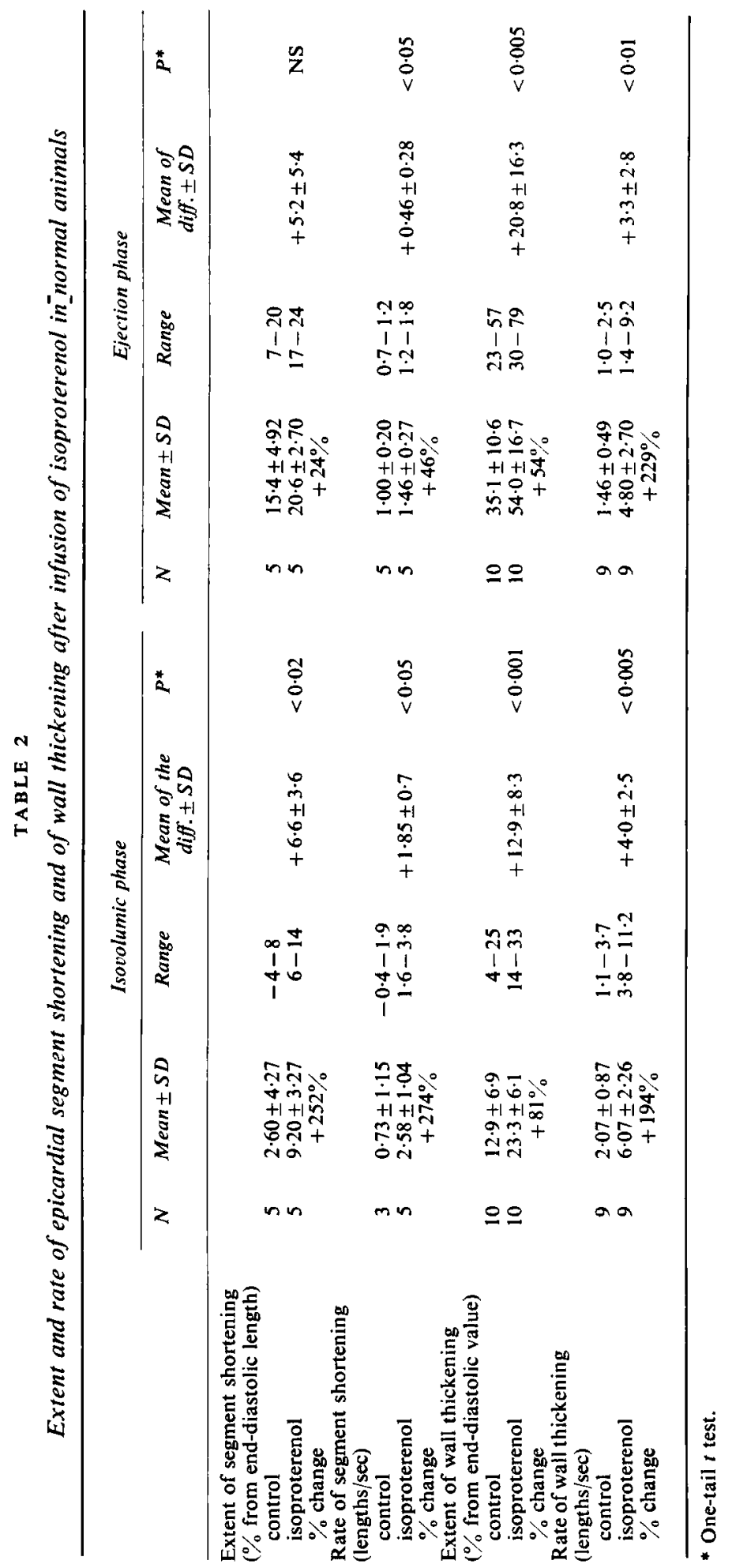




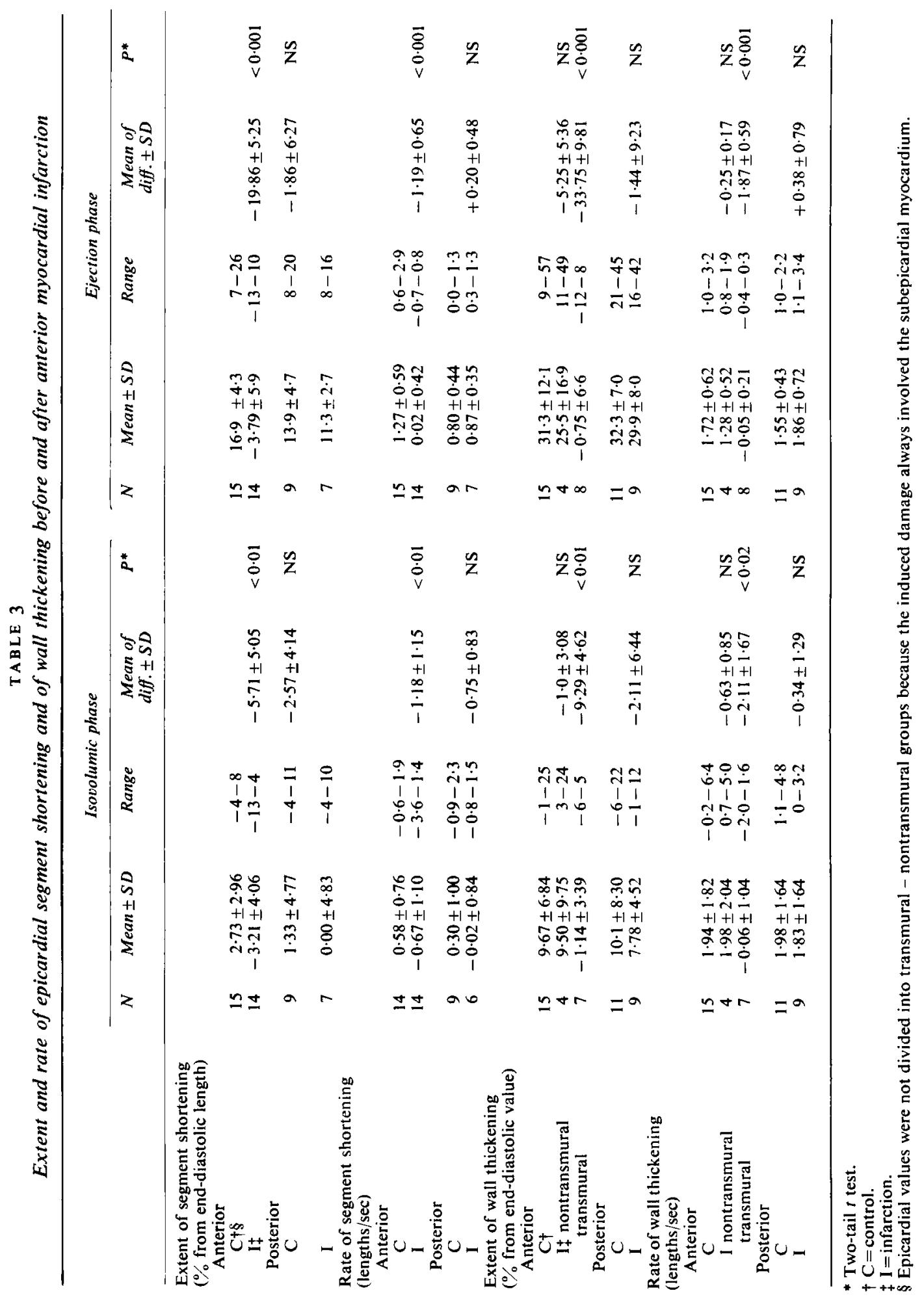



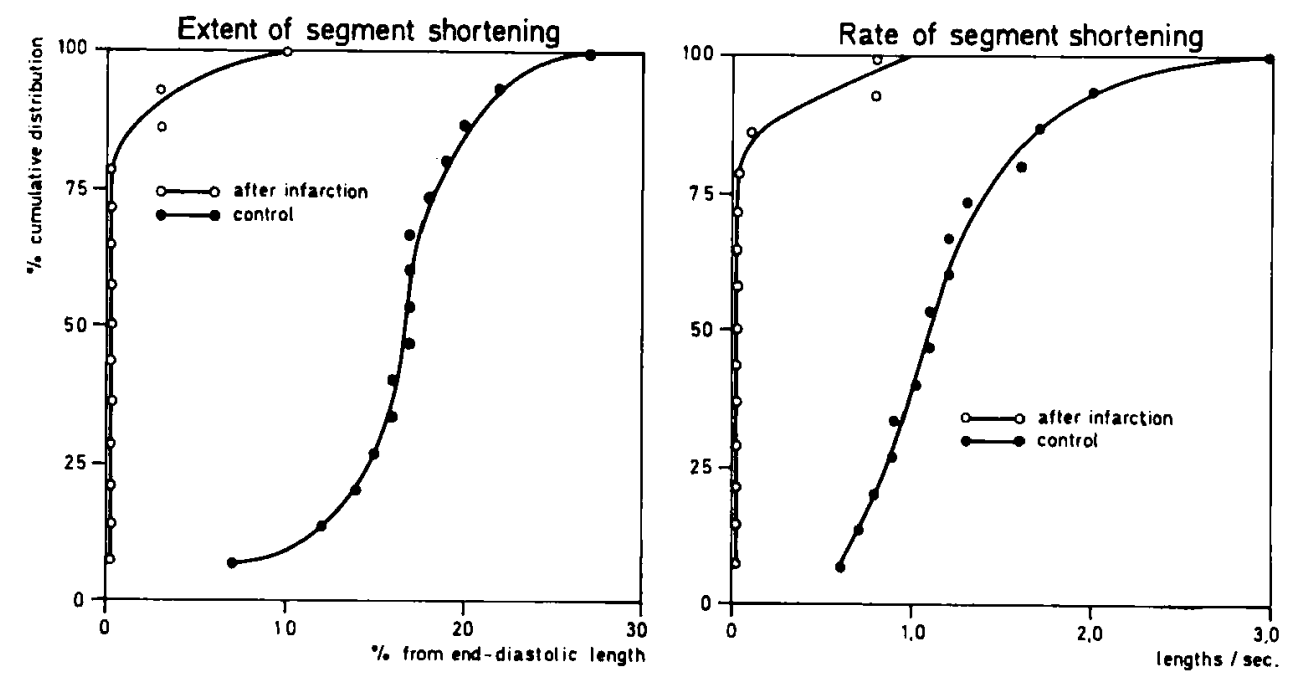

FIG. 7 Cumulative per cent distributions of the individual values of the extent and rate of epicardial segment shortening show good separation of normal and infarcted ventricular areas. Negative values plotted as 0 .
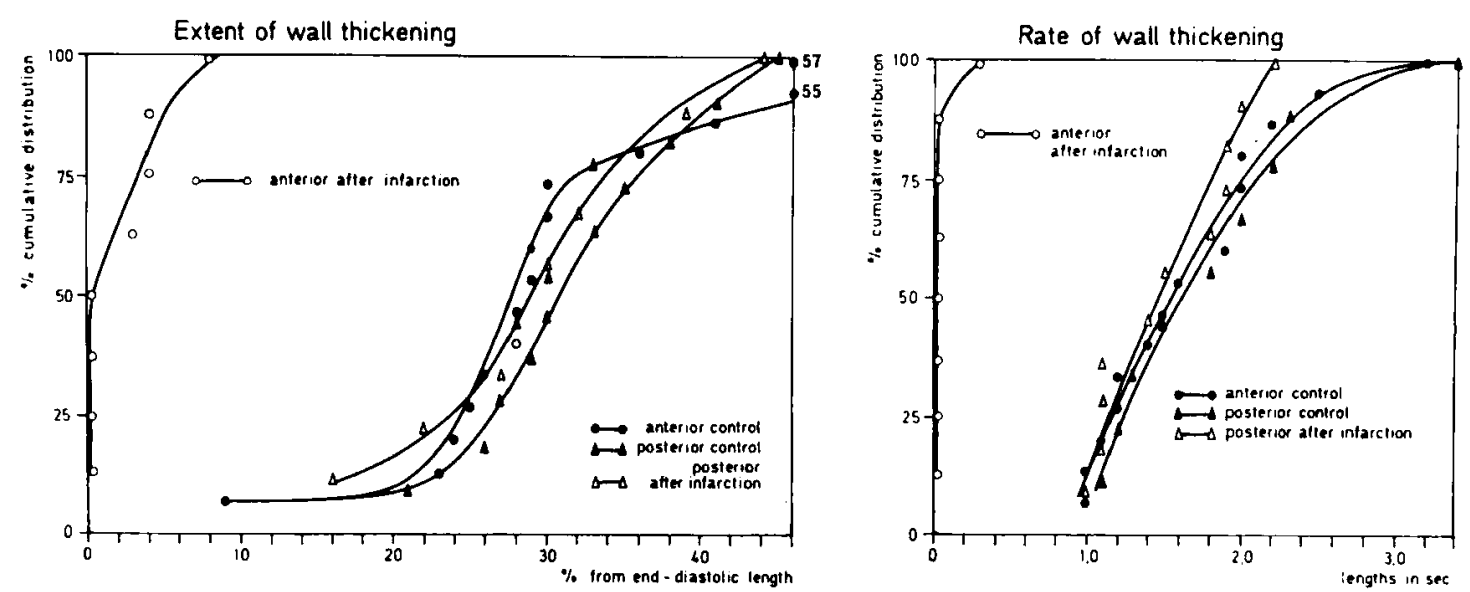

FIG. 8 Cumulative per cent distributions of the individual values of the extent and rate of transmural wall thickening show complete separation of normal and infarcted muscle regions. Negative values plotted as 0.

$9.8 \sec ^{-1}(-4.5 \%$; NS). The end-diastolic segment dimensions measured on the epicardial and endocardial surfaces lengthened significantly after coronary ligation, by a mean of $+8 \cdot 3 \pm$ $8.7 \%$ (SD) $P<0.001$. In the hearts with transmural freezing this elongation was less, $+2 \cdot 2 \pm$ $6.2 \%$; NS, while in hearts with sub-epicardial damage only no lengthening was observed $(-2 \cdot 2$ $\pm 8.3 \%$; NS). The differences between the mean changes in these three groups were significant, $\mathrm{P}<0.01 \quad(\mathrm{~F}[2.63]=6.84)$. The acute ventricular dilatation in animals with major infarction was confirmed in the serial cineventriculograms (Fig. 10). In these experiments the mean increases of the LV end-diastolic pressures were $+6 \cdot 4 \pm 5 \cdot 1$ $(\mathrm{P}<0.05), \quad+2 \cdot 3 \pm 7 \cdot 4 \quad(\mathrm{NS})$, and $+0.2 \pm 3.6$ 


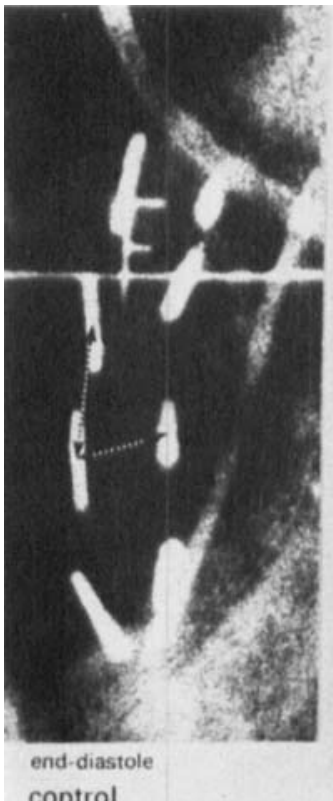

control

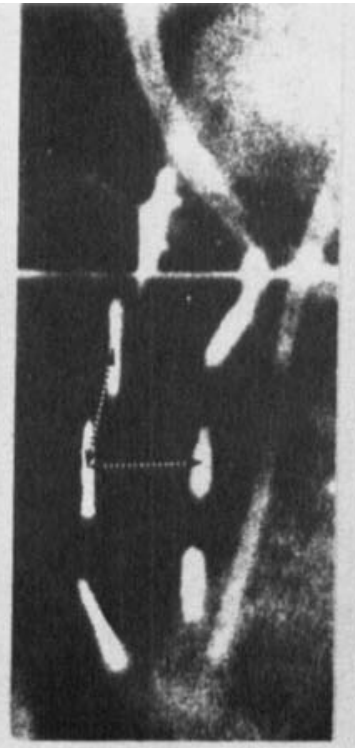

end-systole

$92 \%$

$123 \%$

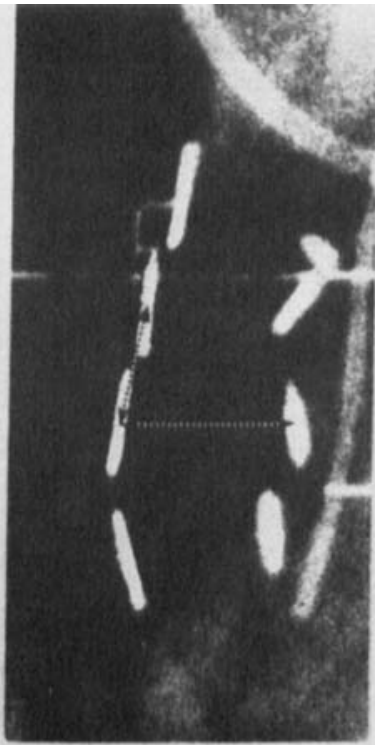

end-systole

isoproterenol

$84 \%$

$186 \%$

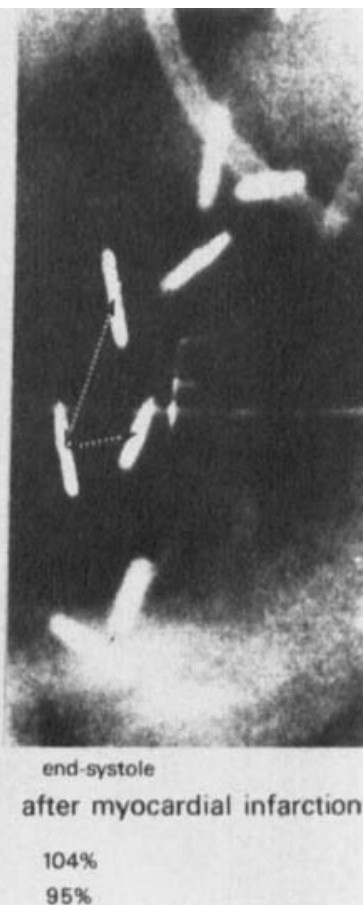

$95 \%$

FIG. 9 Changes of anterior left ventricular epicardial segment lengths and wall thicknesses from enddiastole to end-systole studied by cineradiography of radio-opaque epicardial-endocardial pairs of marker clips. Note the shortening of surface segments in systole and conspicuous further contraction after isoproterenol. In contrast, systolic stretching of the surface segments occur in the ventricular asynergy after myocardial infarction. This was also confirmed by left ventriculographies in every animal (see Fig. 10). The thickness alterations are parallel to the segment length changes. Positioning of the clip planes was adjusted perpendicular to $x$-ray beams in relation to the middle pairs of clips (indicated by dotted arrows).

(NS) $\mathrm{mm} \mathrm{Hg}$ respectively. Peak systolic pressure in the left ventricle decreased by a mean of $-15.6 \pm 3.4 \mathrm{~mm} \mathrm{Hg} ; \mathrm{P}<0.001$, after coronary ligation, but changed insignificantly by $+11 \cdot 2 \pm$ $19.1 \mathrm{~mm} \mathrm{Hg}$ when necrosis was induced by freezing.

\section{Discussion}

\section{Regional contraction of normal left ventricle}

The extent and velocity of epicardial segment shortening in the normal left ventricle of the pig is quite similar to that observed in the human left ventricle by Harrison, Goldblatt, and Braunwald (1963) and by McDonald (1970). There was little difference between different areas in the anterior, lateral, and posterior wall, which indicated a nearly synchronous and uniform order of contraction. Mechanical activation became manifest early during the isovolumic phase of systole, as has been pointed out recently in the human cineventriculographic studies (Karliner, Bouchard, and Gault, 1970; McDonald, 1970).

The degree to which the normal left ventricular wall of the pig thickens $(32 \%)$ is quite close to the data demonstrated by caliper gauge (Feigl and Fry, 1964), implanted lead pellets (Mitchell, Wildenthal, and Mullins, 1969), rapid enddiastolic and end-systolic fixation techniques in dog heart (Ross, Sonnenblick, Covell, Kaiser, and Spiro, 1967), or by transducers placed in the left ventricle in the horse (Cothran, Bowie, Hinds, and Hawthorne, 1967). In the human, 

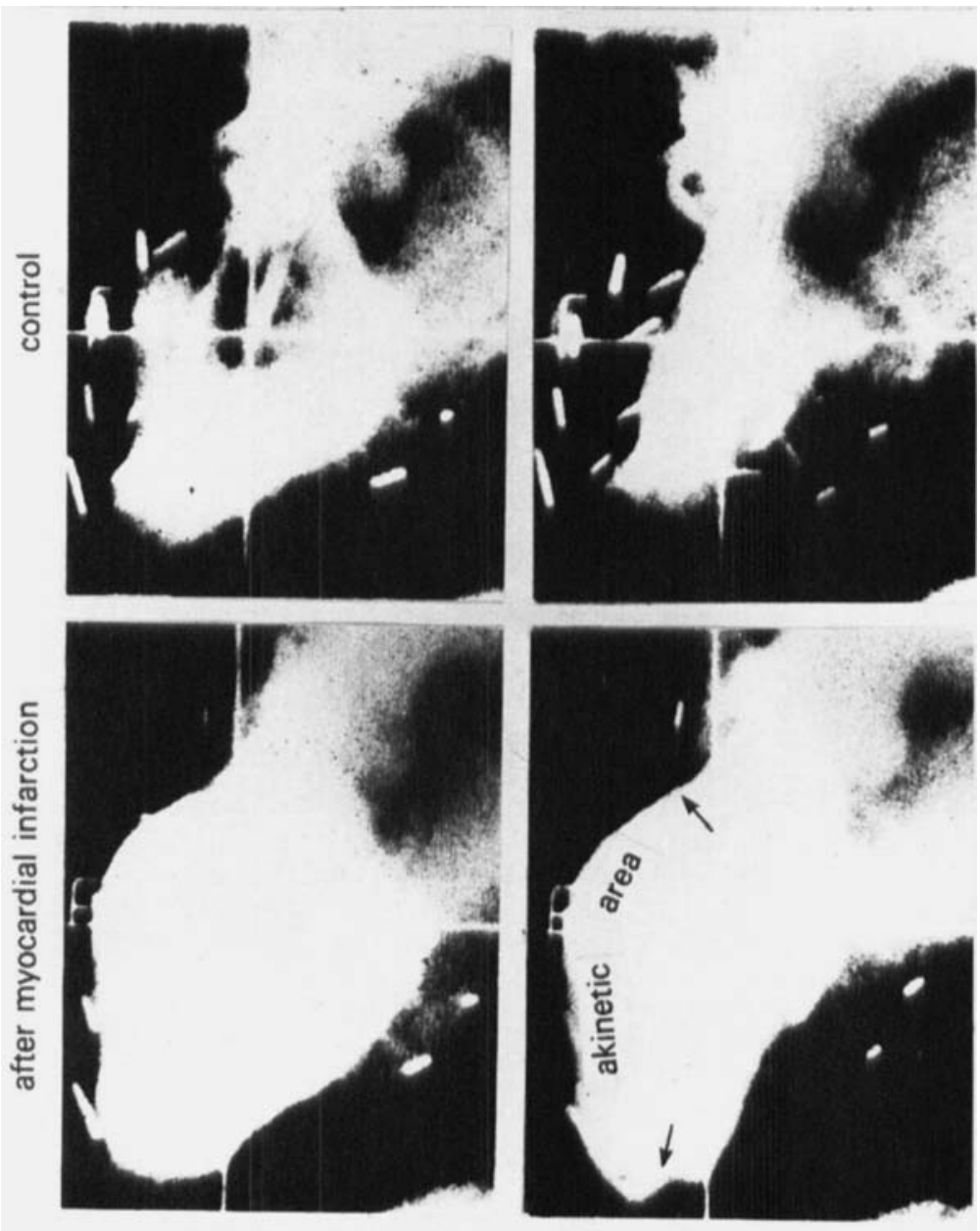

end-diastole

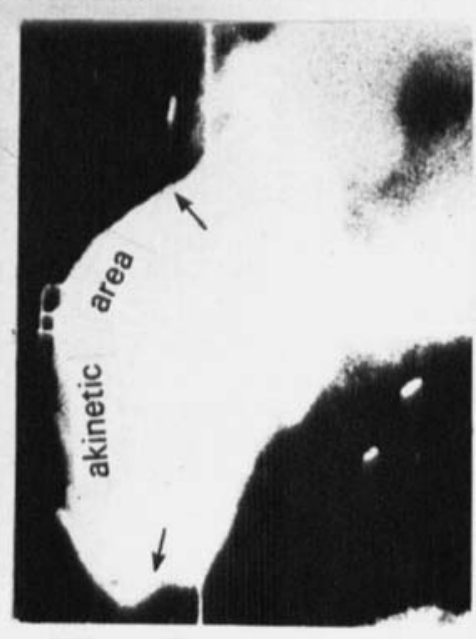

end-systole
FIG. Io Lateral enddiastolic and end-systolic frames from left cineventriculograms demonstrate acute ventricular dilatation and replacement of normal concentric systolic contraction by extensive ventricular asynergy after coronary ligation. The fixed marker letter $F$ reveals the presence of only minimal paradoxical outward pulsation in the akinetic area. The extent of fractional thickening in normal posterior wall was the same before and after infarction both by clips and angiographic contrast.
Hugenholtz, Kaplan, and Hull (1969) reported a mean wall thickening of $39.8 \%$ in those 10 of the 30 patients with congenital heart disease in whom angiocardiography permitted accurate measurement of wall thickness from radiographs. This close agreement between results in different species, and the reproducibility of the results from animal to animal in the present study support the view that the method utilized in this study is a reliable and effective means for the continuous registration of the degree and velocity of shortening of ventricular surface segments and of the extent and rate with which the left ventricular wall thickens. While analysis of myocardial segmental dimensions by the present technique may be influenced by rotational movements of the heart, it has previously been shown that these effects are small (McDonald, 1970). Furthermore, when in this study biplane filming was utilized, the data showed that rotation was not a significant factor.

The fact that the left ventricular wall thickens twice as much as the corresponding epicardial segment shortens is quite striking. While this 
observation is not unexpected when one considers a constant left ventricular muscle mass and an average reduction of end-diastolic volume to $40 \%$ of its original value by the time systolic ejection is terminated, it points out that the measurement of change in wall thickness gives a large signal, which is a better indicator of muscle function than, for example, the intraventricular pressure. Furthermore, the extent to which thickness changes (by a mean of $31.2 \%$ of total wall thickening) during the isovolumic phase of contraction, before opening of the aortic valve is quite remarkable. This latter event occurred in every instance and in the presence of only minor isovolumic shortening of the epicardial segments. Moreover, rapid and considerable early wall thickening was noted in those cases (not included in the present data) where the clips included the body of the papillary muscle in addition to wall thickness. This finding is in good agreement with the early electrical, and mechanical, activation of the endocardial shell of the myocardium and papillary muscles (Durrer, van Dam, Freud, Janse, Meijler, and Arzbaecher, 1970). To what extent these isovolumic changes in myocardial geometry invalidate the use of $\mathrm{dp} / \mathrm{dt} / \mathrm{Kp}$ or Vmax as an indicator of the contractile state remains uncertain, although these differences could well explain some of the discrepancies noted when Vmax calculations derived from LV pressure data were compared with those from real wall stress calculations (Feigl and Fry, 1964; Gault, Kahan, Bouchard, Karliner, and Ross, 1970; Hugenholtz, Ellison, Urschel, Mirsky, and Sonnenblick, 1970; Falsetti, Mates, Greene, and Bunnell, 1971).

\section{Myocardial mechanics in enhanced contractility}

Infusion of isoproterenol uniformly caused augmentation of the extent and rate of changes in wall thickness and of segment contraction. Again, the changes were most striking during the isovolumic phase, although the rate of wall thickening was also enhanced during the ejection phase.

The increase in length and velocity parameters by over $200 \%$ after isoproterenol is closely comparable with the changes in peak rate of force development observed by Beiser, Epstein,
Goldstein, Stampfer, and Braunwald (1970) in intact canine hearts. The marked augmentation in the isovolumic phase of segmental myocardial contraction emphasizes the significance of the concept of Rushmer (1964) and of Noble, Trenchard, and Guz (1966), which states that the major part of the work done by the left ventricle is generated during the sudden forceful impulse which accelerates the intraventricular blood mass for ejection into the aorta.

These findings suggest that the study of the response of wall thickness to inotropic drug during the isovolumic phase may be the optimal manner in which to assess regional ventricular function. In fact, it may be the type of provocation which will define subtle regional dysfunction.

\section{Detection of focal ventricular damage}

One of the most important conclusions to be drawn from these data is that extent and rate of left ventricular wall thickening is more informative than epicardial segment changes regardless of whether normal, enhanced, or depressed cardiac function is present. This is evident from the larger increment in wall thickness measurements as compared with surface segment parameters. Furthermore, during the normal isovolumic contraction, measurements from the epicardium proved to be very variable, while the thickness values showed a consistent pattern. After myocardial infarction, akinesis of the involved segment was immediately evident and could be demonstrated in each instance by disappearance of myocardial thickening.

No compensatory increase in the extent or velocity of contraction was observed in the remaining or adjacent normal muscle areas immediately after myocardial infarction, although in the later stages of infarction this has been proved to occur by Hood, Kumar, Norman, and Abelmann (1970). However, after infarction, resting epicardial segment lengths became significantly longer and ventricular enddiastolic volumes clearly larger when compared with control measurements. It appears thus that the Frank-Starling mechanism becomes effective immediately after infarction has taken place. This augmentation in preload requires no change in the extent and rate of fibre shortening of the 
healthy muscle because of a conspicuously higher wall stress.

The extent to which asynergy of the infarcted segments imposes an extra, and at times, detrimental load to the left ventricle in its contractile and pumping function is probably underestimated. Because major asynergic motions were observed to take place in the isovolumic phase, similarly to early inversion of myocardial tension curves in ischaemia (Yoshida, 1969), much of the force produced by the remaining muscle at that time is spent in realignment of stress in the wall. Thus force available for acceleration of blood for ejection is reduced. For example, in one animal in which the infarct at postmortem examination was shown to involve $\frac{1}{3}$ of the total left ventricular mass, a calculation was carried out to quantitate the increase in wall stress in the remaining healthy muscle imposed by acute ventricular dilatation. From the changes in the radii at that plane in the ventricle and from the pressure generated at that instant it was shown that there was an increase of approximately $200 \%$ in total wall stress. This rough calculation, based on a thin-walled model and utilizing a weighted average of stress and muscle mass, indicates the extent to which ventricular wall energy may be misappropriated.

\section{Clinical implications}

A comparison was made between the clip and the angiographic method for defining the inner boundary of the left ventricular wall. This was done in order to decide whether the changes of wall thickness determined by the angiography would be as accurate as by the clip method. A close correlation was found throughout most of the cycle in delineating the endocardial surface. During the last part of systole the angiographic definition was not always clear in all areas, and the values of wall thickness often abruptly exceeded those obtained by the clip method in endsystole. It has been well demonstrated that difficulties in angiocardiographic assessment of myocardial wall thickness occur only in the later half of systole (Hugenholtz et al., 1969; Karliner et al., 1970). Since the changes in extent and velocity of thickness in impaired myocardial function are clearly present in the isovolumic phase of contraction and because maximum velocity of contraction of ejection takes place during the first half of systole, it is evident that reliable measurements may be derived from angiograms. Further, the angiographic smoothness of the endocardium at the end-systolic phase in severe coronary artery disease or at akinetic areas will aid this analysis.

Since there is close similarity of the normal regional $L V$ function in man and in the normal left ventricle of the pig, the results observed in this experimental study on detection of focal ventricular damage appear to be relevant to man. The clinical application of the wall thickness analysis method in assessment of regional myocardial function is easily performed in many selected areas of the left ventricular wall, and even from single plane ventriculograms, as reported in two patients with coronary artery disease by Eber, Greenberg, Cooke, and Gorlin (1969).

This method may then provide an advantage of simplicity when compared with the elegant method of Kong, Morris, and McIntosh (1970) which assessed segmental myocardial function only from spatial computations of biplane visualization of coronary artery motion. Furthermore, newer developments in ultrasound techniques (Bom, Lancée, Honkoop, and Hugenholtz, 1971; Kraunz and Ryan, 1971) will soon aid in the measurement of wall thickness, as an index of the contractile state of myocardium.

The availability of analysis of regional function of the left ventricle combined with haemodynamic studies is of decisive importance in planning acute or elective surgical resection of an akinetic area after myocardial infarction. In these sometimes urgent situations it is difficult to assess whether critical deterioration of the circulation is due to extensive asynergic areas, or due to generalized diffuse scarring of the musculature. It is suggested that careful analysis of thickness changes of the left ventricular wall in the isovolumic and ejection phase will provide the necessary insight.

We are much indebted to Dr. W. Schaper, Reader in Pathology at the Medical Faculty in Leuven, Belgium and coworker at the Thoraxcenter, Rotterdam, for his suggestions for the method of inducing circumscribed ventricular damage and for performing the detailed pathological-anatomical examinations. The help of Miss Ineke de Widt was invaluable in cineradiographic analysis of segment distances. 


\section{References}

Beiser, G. D., Epstein, S. E., Goldstein, R. E., Stampfer, M., and Braunwald, E. (1970). Comparison of the peak effects of a catecholamine and a digitalis glycoside in the intact canine heart. Circulation, 42, 805-813.

Bom, N., Lancée, C. T. Honkoop, J., and Hugenholtz, P. G. (1971). Ultrasonic viewer for cross-sectional analyses of moving cardiac structures. Bio-Medical Engineering, 6, 500-503.

Braunwald, E., Ross, J., Jr., and Sonnenblick, E. H. (1968). Mechanisms of Contraction of the Normal and Failing Heart. Little, Brown: Boston.

Cothran, L. N., Bowie, W. C., Hinds, J. E., and Hawthorne, E. W. (1967). Left ventricular wall thickness changes in unanesthetized horses. In Factors Influencing Myocardial Contractility, pp. 163-177. Edited by R. D. Tanz, F. Kavaler and J. Roberts. Academic Press: New York.

Durrer, D., Dam, R.Th. van, Freud, G. E., Janse, M. J., Meijler, F. L., and Arzbaecher, R. C. (1970). Total excitation of the isolated human heart. Circulation, 41, 899-912.

Eber, L. M., Greenberg, H. M., Cooke, J. M., and Gorlin, R. (1969). Dynamic changes in left ventricular free wall thickness in the human heart. Circulation, 39, 455-464.

Falsetti, H. L., Mates, R. E., Greene, D. G., and Bunnell, 1. L. (1971). Vmax as an index of contractile state in man. Circulation, 43, 467-479.

Feigl, E. O., and Fry, D. L. (1964). Myocardial mural thickness during the cardiac cycle. Circulation Research, 14, 541-545.

Gault, J. H., Kahan, R., Bouchard, R., Karliner, J. S., and Ross, J., Jr. (1970). Comparison of maximal contractile element velocity (Vmax) and tension-velocity measurements during ejection as estimates of left ventricular contractility. (Abstract.) American Journal of Cardiology, 25, 97.

Gault, J. H., Ross, J., Jr., and Braunwald, E. (1968). Contractile state of the left ventricle in man: instantaneous tensionvelocity-length relations in patients with and without disease of the left ventricular myocardium. Circulation Research, 22, 451-463.

Harrison, D. C., Goldblatt, A., and Braunwald, E. (1963). Studies on cardiac dimensions in intact, unanesthetized man. Circulation Research, 13, 448-467.

Heikkilä, J., Luomanmäki, K., and Pyörälä, K. (1971). Serial observations on left ventricular dysfunction in acute myocardial infarction. I. Gallop sounds, ventricular asynergy and radiologial signs. Acta Medica Scandinavica, $190,89-104$.

Hood, W. B., Jr., Kumar, R., Norman, J. C., and Abelmann, W. H. (1970). Experimental canine myocardial infarction: serial changes in ventricular function related to mechanical properties of normal and infarcted myocardium. Cardiotascular Research, VI Word Congress of Cardiology, Abstracts of papers, p. 167. B.M.A.: London.

Hugenholtz, P. G., Kaplan, E., and Hull, E. (1969). Determination of left ventricular wall thickness by angiocardiography. American Heart Journal, 78, 513-522.
Hugenholtz, P. G., Ellison, R. C., Urschel, C. W., Mirsky, I., and Sonnenblick, E. H. (1970). Myocardial force-velocity relationships in clinical heart disease. Circulation, 41, 191-202.

Karliner, J., Bouchard, R., and Gault, J. (1970). Left ventricular geometry prior to aortic valve opening in man. (Abstract.) Circulation, 42, Suppl. 3, 60.

Kong, Y., Morris, J. J., Jr., and Mclntosh, H. D. (1970). Assessment of regional myocardial performance from biplane coronary cineangiograms. (Abstract.) American Journal of Cardiology, 25, 374-375.

Kraunz, R. F., and Ryan, T. J. (1971). Ultrasound measurements of ventricular wall motion following administration of vasoactive drugs. American Journal of Cardiology, 27, 464-473.

McDonald, I. G. (1970). The shape and movements of the human left ventricle during systole. Study by cineangiography and by cineradiography of epicardial markers. American Journal of Cardiology, 26, 221-230.

Mason, D. T., Spann, J. F. Jr., Zelis, R., and Amsterdam, E. A. (1970). Alterations of hemodynamics and myocardial mechanics in patients with congestive heart failure: pathophysiologic mechanisms and assessment of cardiac function and ventricular contractility. Progress in Cardiovascular Diseases, 12, 507-557.

Milstein, B. B. (1970). Exploring surgical treatment for myocardial infarction. British Heart Journal, 32, 421-426.

Mitchell, J. H., Wildenthal, K., and Mullins, C. B. (1969). Geometrical studies of the left ventricle utilizing biplane cinefluorography. Federation Proceedings, 28, 1334-1343.

Noble, M. I. M., Trenchard, D., and Guz, A. (1966). Left ventricular ejection in conscious dogs: 1 . Measurement and significance of the maximum acceleration of blood from the left ventricle. Circulation Research, 19, 139-147.

Pairolero, P. C., McCallister, B. D., Hallermann, F. J., and Ellis, F. H., Jr. (1970). Experimental production and hemodynamic effects of left ventricular akinesis. (Abstract.) American Journal of Cardiology, 25, 120.

Ross, J., Jr., Sonnenblick, E. H., Covell, J. W., Kaiser, G. A., and Spiro, D. (1967). The architecture of the heart in systole and diastole. Technique of rapid fixation and analysis of left ventricular geometry. Circulation Research, 21, 409-421.

Rushmer, R. F. (1964). Initial ventricular impulse. A potential key to cardiac evaluation. Circulation, 29, 268-283.

Sonnenblick, E. H., Parmley, W. W., Urschel, C. W., and Brutsaert, D. L. (1970). Ventricular function: evaluation of myocardial contractility in health and disease. Progress in Cardiovascular Diseases, 12, 449-466.

Tennant, R., and Wiggers, C. J. (1935). The effect of coronary occlusion on myocardial contraction. American Journal of Physiology, 112, 351-361.

Yoshida, S. (1969). Experimental studies of coronary insufficiency. I. Changes in myocardial contractility in the ischemic area of the ventricle following acute coronary occlusion. Japanese Circulation Journal, 33, 1253-1258. 